IZA DP No. 4346

Real and Nominal Wage Rigidity in a Model of Equal-Treatment Contracting

Pedro Martins

Andy Snell

Jonathan P. Thomas

August 2009 


\title{
Real and Nominal Wage Rigidity in a Model of Equal-Treatment Contracting
}

\author{
Pedro Martins \\ Queen Mary, University of London, \\ CEG-IST Lisbon and IZA \\ Andy Snell \\ University of Edinburgh \\ Jonathan P. Thomas \\ University of Edinburgh
}
Discussion Paper No. 4346
August 2009

\author{
IZA \\ P.O. Box 7240 \\ 53072 Bonn \\ Germany \\ Phone: +49-228-3894-0 \\ Fax: +49-228-3894-180 \\ E-mail: iza@iza.org
}

\begin{abstract}
Any opinions expressed here are those of the author(s) and not those of IZA. Research published in this series may include views on policy, but the institute itself takes no institutional policy positions.

The Institute for the Study of Labor (IZA) in Bonn is a local and virtual international research center and a place of communication between science, politics and business. IZA is an independent nonprofit organization supported by Deutsche Post Foundation. The center is associated with the University of Bonn and offers a stimulating research environment through its international network, workshops and conferences, data service, project support, research visits and doctoral program. IZA engages in (i) original and internationally competitive research in all fields of labor economics, (ii) development of policy concepts, and (iii) dissemination of research results and concepts to the interested public.
\end{abstract}

IZA Discussion Papers often represent preliminary work and are circulated to encourage discussion. Citation of such a paper should account for its provisional character. A revised version may be available directly from the author. 
IZA Discussion Paper No. 4346

August 2009

\section{ABSTRACT}

\section{Real and Nominal Wage Rigidity in a Model of Equal-Treatment Contracting*}

Following insights by Bewley (1999a), this paper analyses a model with downward rigidities in which firms cannot pay discriminate based on a year of entry to a firm, and develops an equilibrium model of wages and unemployment. We solve for the dynamics of wages and unemployment under conditions of downward wage rigidity, where forward looking firms take into account these constraints. Using simulated productivity data based on the post-war US economy, we analyse the ability of the model to match certain stylised labour market facts.

JEL Classification: E32, J41

Keywords: labour contracts, business cycle, unemployment, equal treatment, downward rigidity, cross-contract restrictions

Corresponding author:

Pedro Martins

School of Business and Management

Queen Mary, University of London

Mile End Road

London E1 4NS

United Kingdom

E-mail: p.martins@qmul.ac.uk

\footnotetext{
* We are grateful for comments from Nobu Kiyotaki, John Moore, and participants at the Centre for Dynamic Macroeconomic Analaysis conference in St. Andrews.
} 


\section{Introduction}

Truman Bewley has argued that there are two key features constraining wage cuts for new hires in recessions (Bewley (1999a)). Because wage cuts for incumbents will have a negative impact on morale, firms avoid them under all but extreme circumstance; at the same time while new hires may be willing to work at a lower wage than that paid to incumbents, paying them less would disrupt internal equity and so their wages will be set at the same level as incumbents':

New employees, in contrast, feel it is inequitable to be paid according to a scale lower than the one that applied to colleagues that were hired earlier. For this reason, downward pay rigidity for new hires exists only because the pay of existing employees is rigid. (Bewley (1999b))

Bewley's account mainly concentrates on the question of why firms do not cut wages in recession. But it raises the important question of how forward looking firms take into account the fact that such constraints - downward rigidity combined with "equal treatment" of new hires - may arise in the future. For example, a firm, anticipating downward wage rigidity, may temper wage increases in better times. ${ }^{1}$ Or in more generality, and supposing that firms can offer long-term contracts, the firm must take into account these equal treatment constraints which may prevent it bringing in new hires at a low wage in downturns, and also prevent the firm hiring at a higher wage than that offered to incumbents when the labour market is tight. ${ }^{2}$ What are the implications for wages and employment in an equilibrium model with forward looking firms and workers?

In order to analyse the dynamic consequences of Bewley's insights, we analyse a model in which the pay of new hires and existing workers is linked within each firm-indeed is identical, given that we assume all workers are perfect substitutes - and in which the pay of incumbents is subject to some downward rigidity. This rigidity is then transmitted to the pay of new hires. ${ }^{3}$ Workers and firms then must anticipate the effects of this, so that

\footnotetext{
${ }^{1}$ Note that in the absence of equal treatment, downward rigidity would not normally be an issue (indeed downward rigid wage contracts are optimal in the environment studied by Beaudry and DiNardo (1991)). Future new hires would have a contract tailored to their circumstances, and this is independent of devising an optimal contract for current hires.

${ }^{2}$ Bringing in workers at higher pay than incumbents is even more problematic; thus while-in contrast to the primary sector-Bewley found evidence that new hires are sometimes paid a lower rate than incumbents in the secondary sector, even there, paying new hires more than incumbents is deemed to be very disruptive (Bewley (1999a, p. 320)).

${ }^{3}$ We stress the point that for there to be significant labour market implications it is necessary that downward rigidity applies to new hires - if it only applies to incumbent workers so that new hires can be hired at a flexible wage, there is no reason why hiring decisions should not be efficient.
} 
for example an increase in current wages means that future wages cannot be cut below this level. Despite the enormous literature which exists on downward rigidities, there has been almost no analysis of the forward looking nature of the decision problem and its labor market implications (the only exception we are aware of is Elsby (2009), who solves a problem involving downward nominal rigidities, but in a very different context).

To do this, we take the equal treatment model of Snell and Thomas (2009) and add an explicit downward rigidity constraint. ${ }^{4}$ We do not, it should be stressed, attempt to provide an explicit foundation for the two constraints. ${ }^{5}$ In the unrestricted model - without the downward rigidity restriction - because of equal treatment of workers firms have to tradeoff the desire to insure their risk-averse workers against the need to respond to market conditions to not only prevent their workers from quitting, but also to take advantage of states of the world where labour is cheap. The insurance motive alone provides a degree of downward rigidity. In this paper we add to this model downward wage restrictions in the spirit of Bewley to see how the performance of the model changes. A firm will face not only a sequence of participation constraints if it needs to retain existing, or hire in new, workers, but also a constraint each period restricting the degree to which it can cut its wage. A major challenge of the analysis is to solve for an equilibrium in the face of these constraints.

The equal treatment assumption prevents firms from cutting wages for new entrants, so that in periods with adverse shocks the wage may not fall sufficiently to clear the labour market. In the absence of equal treatment, wage rigidity in this model (with fixed hours) would not have employment effects, as utilities offered to new entrants would be flexible. We show however that (under certain conditions) firms hire up to the point where the real wage equals the marginal product of labour; to the extent then that wages do not correspond to market-clearing levels hiring will be inefficient; in fact we show that this occurs only in the direction of wages being too high leading to inefficiently low employment and an excess supply of labour.

For the case where there is no uncertainty (so firms perfectly anticipate all future productivity changes) we are able to provide a complete characterization of equilibrium provided that the downward rigidity constraint is not too loose (does not allow too large a reduction in real wages). In fact this characterization is very simple and intuitive: first calculate the spot wage for a particular date with its corresponding productivity level:

\footnotetext{
${ }^{4}$ We also extend that model to multiple sectors, an extension which is crucial for addressing recent empirical evidence.

${ }^{5}$ Snell and Thomas (2009) show how equal treatment can be endogenised if the contracting environment is "at will" and a similar argument could be used here (see also Menzio and Moen (2008)). A related argument in the insider-outsider context has been made by Gottfries and Sjostrom (2000).
} 
this is the wage that would clear the labour market in that period if firms were unable to offer long-term contracts. If this lies below the minimum wage for that period, i.e., that calculated by applying the downward rigidity constraint to the wage in the previous period (this minimum wage is just the lagged wage if there is complete downward rigidity), then the wage will be at its minimum level (and there will be unemployment because the wage is too high, recalling that firms hire on their labour demand curves). On the other hand if the spot wage in a particular period is above the minimum wage, then the new wage is simply set to the spot wage and there is no unemployment. Intuitively, in this case, firms cannot hold wages down because of competitive pressures forcing up the utility that must be offered to reatin and hire. (They could hold current wages down and promise more in the future to compensate, but this would be a costlier contract.) Given that the initial wage is at the spot level, this allows for the model to be solved. Unfortunately this result doesn't fully generalise to the case with uncertainty, although we present a result for a two-period model.

Not only do we solve for an equilibrium of a model when forward looking firms have downward constraints, but we also look at whether the equilibrium wage and unemployment dynamics look reasonable. We argue that our model, when simulated with sectoral productivity shocks, is capable of generating simulation results that are reasonably consistent with empirical unemployment and wage movements over the business cycle.

An outline of the paper is as follows. We start by looking at whether ther is evidence for the equal treatment assumption in Section 2. Then we lay out the basic assumptions of our model in Section 3 and the next two subsections. In Section 3.1.2 we prove a simple characterization of the equilibrium when there is no uncertainty. In Section 3.1.3 we discuss to what extent these results extend to the uncertainty case. In Section 4 we simulate the model using simulated and actual sectoral TFP data from the postwar US economy to generate predictions of wage and unemployment movements, and see to what extent these satisfy certain stylised facts. Finally Section 5 contains concluding comments.

\section{Evidence for equal treatment}

While we simply impose that all workers within a firm mustbe paid the same, we here briefly review the empirical evidence on the issue of equal treatment. An early study was Baker, Gibbs, and Holmstrom (1994), who examined the pay of managerial employees in a single firm over time. They found that incumbents' pay tends to move together, but the pay of entrants is significantly more variable, suggesting that the pay of new hires may be 
more subject to outside conditions than that of incumbents.However they do not formally control for composition of entry cohorts, so it is difficult to know what the cause of this extra variability is. Wachter and Bender (2008) have recently run a similar analysis on a number of firms in a large German manufacturing sector, and they, too, find evidence of substantial and quite persistent entry cohort effects. However these seem to be widely distributed across firms at any given date, suggesting, as they note, that they are not driven by cyclical phenomena. A study by Kwon and Milgrom (2005) of Swedish workers finds that if cohort effects for labor market entry and occupation entry are included in addition to firm entry cohort effects, the former two are procyclical in line with expectation, while the latter actually appear countercyclical. In other words, a worker entering the labour market in a downturn will tend to do worse than those already active, but entering a firm in a downturn does not of itself lead to a lower wage than that received by incumbents; in fact the opposite appears to be the case. Haefke, Sonntag, and van Rens (2007) construct a representative series for US wages of new hires (based on the CPS); in their definition new hires consist of workers who were without work in the previous 4 months, and consequently includes those hired from the pool of unemployed along with workers entering from outside of the labor market. They argue that this series shows substantially more variability than the comparable one for those who remain in work, and indeed varies roughly one-for-one with productivity, in line with the basic matching model. ${ }^{6}$ We do not regard this as fatal for our assumption however: a higher aggregate variability across sectors of new hire wages relative to incumbents does not necessarily imply the same is true within each sector, and certainly does not imply that new hires are treated differently within each firm. We hope to develop the model to address this issue in the future. In a similar vein, Pissarides (2007) summarises empirical studies that find wages for workers who change jobs are considerably more procyclical than those who remain with the same employer (see Footnote 6). Gertler and Trigari (2009), however, argue that such studies are not demonstrating that the new hire wage is more procyclical than a stayer's wage within a particular firm. The reason for the empirical finding could simply be that match quality varies procyclically, and they

\footnotetext{
${ }^{6}$ This issue has arisen in the debate since Shimer (2005a) about whether the Mortensen-Pissarides matching model is capable of generating sufficient variability of the vacancies to unemployment ratio from plausibly sized productivity variations. One answer to this has been to posit that real wages do not vary as much as the Nash bargaining approach implies, thus giving rise to increased cyclical effects (Hall 2005a). While this gives a satisfactory theoretical resolution of the difficulty, Pissarides (2007) points out that one can look at the empirical studies to see which story about wages looks more reasonable. Pissarides also points out that it is the estimated wage elasticity for new matches that should be used in the above exercise, since it is these wages which determine the profitability of a new match and hence drive job creation. Looking at the cyclicality of wages for workers who change jobs, his conclusion is that the resolution of positing more rigid wages leads to an empirically implausible degree of wage rigidity, and one should look elsewhere to resolve this question. However, as argued below, the interpretation of these empirical studies is open to question.
} 
present evidence supporting their point of view.

Finally, as discussed above, survey evidence in Bewley (1999a) suggests that violations of equal treatment are unusual, particularly in the primary sector. Similar findings exist for other countries: "Managers responded that hiring underbidders would violate their internal wage policy" (Agell and Lundborg (2003, p.7), based on a Swedish survey); in a British survey, Kaufman (1984) reported that almost all managers viewed bringing in similarly qualified workers at lower wage rates as "infeasible." Akerlof and Yellen (1990) argue that personnel management texts treat the need for equitable pay as virtually selfevident.

\section{The model}

The model is as follows. Time runs from $t=1,2,3, \ldots, T$, where $T \geq 2$ is finite, and there is a single consumption good each period (all wages below are real wages). There are $M$ equal sized sectors. All workers are assumed to be identical, except for the date at which they enter the labor market, and the sector to which they are currently associated (we abstract from any tenure or experience effects on productivity). Workers are risk averse with per period twice differentiable utility function $u(w), u^{\prime}>0, u^{\prime \prime}<0$, where $w \geq 0$ is the income which must be consumed within the period; it is assumed that they can neither save nor borrow. There is no disutility of work, but hours are fixed so that workers are either employed or unemployed. Assume that if workers are not employed in a period, they receive some low consumption level $\underline{c}>0$. There is a large (but fixed) number of identical risk-neutral firms in each sector. A firm in sector $m$ has a diminishing returns technology where output is $F^{m}\left(N, s_{t}\right)$ with $\partial F^{m} / \partial N>0, \partial^{2} F^{m} / \partial N^{2}<0$, where $N$ is labour input and $s_{t}$ is the current shock (which specifies current productivity in each sector). It is assumed that a firm must always employ some (minimum measure of) workers each period. ${ }^{7}$ Workers and firms discount the future with common factor $\beta \in(0,1]$.

For an employed worker, there is a "staying" probability of $\delta \in(0,1)$, each period, with workers exogenously separating with probability $1-\delta$; moreover with probability $\mu$ separated workers must seek work at a different firm and with probability $1-\mu$ they die (exit the market); of the surviving separated, a proportion $\phi$ remain in the same sector while $(1-\phi)$ are distributed evenly across sectors. The same death probability of $(1-\delta)(1-\mu)$ applies to the unemployed, and likewise $(1-\phi)$ of the surviving unemployed move to other sectors. Separation occurs at the end of a period so that separated workers

\footnotetext{
${ }^{7}$ This can be motivated by an assumption that firms cannot produce after a period of zero production.
} 
who do not die but find a job in the following period do not suffer any unemployment. The number dying is replaced by the same number of new entrants, so that each sector maintains its size. (Thus all movements between firms and between sectors are due to exogenous separations and workers cannot choose, for example, which sector to move to, or enter.) We assume there are a large number of workers relative to the number of firms, and we normalize the ratio of workers to firms to be one in each sector and each period. ${ }^{8}$ We assume that the "spot wage" / full employment solution $(N=1)$ is always greater than the unemployment consumption level, i.e., that $\partial F^{m} / \partial N\left(1, s_{t}\right)>\underline{c}$ all $t$.

The shock $s_{t}$ follows a stochastic process taking a finite number of possible values, and with initial value $s_{1}$, which we specify in more detail below. Let $h_{t} \equiv\left(s_{1}, s_{2}, \ldots, s_{t}\right)$ be the history at $t$. The labour market offers a worker currently looking for work in sector $m$ (at the start of $t$, discounted to $t$ ) of $\chi_{t}^{m}=\chi_{t}^{m}\left(h_{t}\right)$ : this is an average of the utility from remaining unemployed and that from from getting a job where the weight depends on the probability of being hired as described below. A firm must offer at least $\chi_{t}^{m}\left(h_{t}\right)$ to prevent its workers from quitting, and this is also the minimum utility that must be offered to hire: We assume that the firm can hire any number of workers by offering at least $\chi_{t}^{m}$ (and cannot hire otherwise). So the labour market is modelled as being competitive.

We summarise the timing as follows. At date 1 each firm in sector $m$ offers a single state-contingent wage contract $\left(w_{t}^{m}\left(h_{t}\right)\right)_{t=1}^{T}$ to which it is committed. Workers then can accept contracts and period 1 production takes place. At the end of period 1, a firm loses a fraction $(1-\delta)$ of its workforce due to exogenous separation, as described above. At the start of each subsequent period $t \geq 2$, firms and workers observe $s_{t}$. Workers may quit costlessly at this point and join the pool of those previously separated, surviving unemployed and new entrants to the sector, facing the same probability of employment (so receive $\left.\chi_{t}^{m}\left(h_{t}\right)\right)$, but may not switch sectors. However, provided the continuation utility offered by the contract at least matches $\chi_{t}^{m}$, the firm is able to retain its staff and hire in as many new workers as it requires from the pool of those looking for work. Production takes place and wages $w_{t}^{m}\left(h_{t}\right)$ are paid, and so on.

\subsection{The Firm's problem}

We work with a representative firm in sector $m$. At the start of date 1 , after $s_{1}$ is observed, as just stated, firms in each sector $m$ commit to contracts $\left(w_{t}^{m}\left(h_{t}\right)\right)_{t=1}^{T}, w_{t}^{m}\left(h_{t}\right) \geq 0$, which

\footnotetext{
${ }^{8}$ While these different probabilities make the model rather involved, it turns out that under certain conditions they do not matter for the equilibrium wage paths when downward rigidity is imposed. This would not be true if workers were able to choose which sectors to enter, an extension we plan to make in the future.
} 
we assume are not binding on workers. We assume equal treatment within the firm: a worker joining subsequently, at $\tau$ after history $h_{\tau}$, is offered a continuation of this same contract: $\left(w_{t}^{m}\left(h_{t}\right)\right)_{t=\tau}^{T}$. (This is to be contrasted with the case where discrimination is permitted where a worker joining at $\tau$ would be offered a contract which in principle may be unrelated to that offered to previous cohorts.) To avoid cluttering the notation, we omit sector superscripts in what follows unless necessary (so an omitted superscript implies that the sector is $m$ ). Let $V_{t}\left(h_{t}\right)$ denote the continuation utility from $t$ onwards from the contract, defined recursively by:

$$
\begin{aligned}
V_{t}\left(h_{t}\right)= & u\left(w_{t}\left(h_{t}\right)\right)+\beta_{w}\left[E \delta V_{t+1}\left(h_{t+1}\right)+\right. \\
& \left.(1-\delta) \mu \phi \chi_{t+1}+\sum_{m^{\prime} \neq m}(M-1)^{-1}(1-\delta) \mu(1-\phi) \chi_{t+1}^{m^{\prime}} \mid h_{t}\right],
\end{aligned}
$$

with $V_{T+1}=0$, where $E$ denotes expectation, and the terms involving $\chi_{t+1}$ and $\chi_{t+1}^{m^{\prime}}$ reflect the utility after exogenous separation but no death, if the worker respectively remains in the same sector or moves to another sector. Each firm also has a planned employment path $\left(N_{t}\left(h_{t}\right)\right)_{t=1}^{T}$, where $N_{t}\left(h_{t}\right) \geq 0$.

Note that in (1) it is assumed that there are no layoffs, only exogenously determined separations. Our aim is to construct an equilibrium in which layoffs do not occur, largely because it substantially simplifies the analytics of the solution. In fact, we will state the optimization problem below imposing no layoffs, to avoid complicating the statement of the problem, and later derive parameter restrictions for which this remains a solution even if layoffs are permitted. ${ }^{9}$

The problem faced by the firm, which takes the stochastic sequence of outside option values in its sector, $\left(\chi_{t}\right)_{t=1}^{T}$, as parametric (as well as those in other sectors), is:

$$
\max _{\left(w_{t}\left(h_{t}\right)\right)_{t=1}^{T},\left(N_{t}\left(h_{t}\right)\right)_{t=1}^{T}} E\left[\sum_{t=1}^{T}\left(\beta_{f}\right)^{t-1}\left(F^{m}\left(N_{t}\left(h_{t}\right), s_{t}\right)-N_{t}\left(h_{t}\right) w_{t}\left(h_{t}\right)\right)\right] \quad \text { (Problem DWR) }
$$

subject to

$$
V_{t}\left(h_{t}\right) \geq \chi_{t}\left(h_{t}\right)
$$

for all positive probability $h_{t}, T \geq t \geq 1$,

$$
w_{t}\left(h_{t-1}, s\right) \geq b\left(h_{t-1}, s\right) w\left(h_{t-1}\right),
$$

\footnotetext{
${ }^{9}$ The details of this final step are developed in Snell and Thomas (2009) and apply mutatis mutandis. Given that the rate of separation is exogenous, it is changes in hiring that drive movements in unemployment in our model. This is consistent with Hall (2005b), who argues that the separation rate in the US labor market is roughly constant (see also Pissarides (1986), Shimer (2005b)), and that although job losses rise during recessions, the increase is usually very small in relation to the normal levels of separations. However, these conclusions have been disputed (see Elsby, Michaels, and Solon (2009)).
} 
and

$$
N_{t}\left(h_{t-1}, s\right) \geq \delta N_{t-1}\left(h_{t-1}\right)
$$

for all positive probability $h_{t-1}$, all $s \in S$ with $\pi_{s_{t-1} s}>0, T \geq t \geq 2$. (2) is the participation constraint that says that at any point the contract must offer at least what a worker can get by quitting, and (3) is the ad hoc downward constraint that imposes that wages cannot fall at a rate faster than an amount which may depend on the current state (e.g., to capture inflation), given by $b\left(h_{t}\right)$. For $b=1$ we have downward real wage rigidity, and for $b=0$ we have the problem in which there is no downward constraint on wages. Downward nominal rigidity would be captured by $b\left(h_{t}\right)=p_{t-1} / p_{t}$, where $p_{t}$ is the price level at $t$ (prices play no other role in this model). Finally, (4) imposes that the firm may not layoff workers. ${ }^{10}$ We shall also consider a modified version of Problem DWR in which we ignore the constraint (4); we refer to this as Problem DWR'.

\subsubsection{Equilibrium}

We shall use a $*$ superscript to denote equilibrium values. ${ }^{11}$ We are looking for symmetric solutions, i.e., where all firms in a sector choose the same contract (though we do not need symmetry across sectors). To close the model we impose an equation specifying the equilibrium determination, given $\left(w_{t}^{*}\left(h_{t}\right)\right)_{t=1}^{T},\left(N_{t}^{*}\left(h_{t}\right)\right)_{t=1}^{T}$, of the outside option in sector $m:$

$$
\chi_{t}=\frac{N_{t}^{*}-\delta N_{t-1}^{*}}{1-\delta N_{t-1}^{*}} V_{t}^{*}+\frac{1-N_{t}^{*}}{1-\delta N_{t-1}^{*}} U_{t}
$$

$N_{0}^{*}=0$, where $V_{t}^{*}$ is the equilibrium contract offer at $t$ (the denominator is the number of workers not retained after $t-1$, which equals the number seeking work at $t$, while the numerator in the first fraction is the number of hires at $t$ ). $U_{t}$ is the discounted utility of a worker who is unemployed at $t$ which is given by

$$
\begin{aligned}
U_{t}\left(h_{t}\right)= & u(\underline{c})+\beta_{w}(1-(1-\delta)(1-\mu))\left(\phi E\left[\chi_{t+1} \mid h_{t}\right]+\right. \\
& \left.\sum_{m^{\prime} \neq m}(M-1)^{-1}(1-\phi) E\left[\chi_{t+1}^{m^{\prime}} \mid h_{t}\right]\right),
\end{aligned}
$$

i.e., the utility from the reservation wage plus future utility assuming survival (with probability $(1-(1-\delta)(1-\mu)))$ from not having a job at the beginning of $t+1$. Given the endpoint condition $\chi_{T+1}^{m^{\prime}}=0$, all $m^{\prime},(5),(1)$ and (6) uniquely determine $U_{t}, V_{t}^{*}$ and $\chi_{t}$.

\footnotetext{
${ }^{10}$ More precisely, (4) implies layoffs are not needed. However the definition of $V_{t}\left(h_{t}\right)$ in $(1)$ implies that a worker remains with the firm unless exogenously separated, so together these two assumptions rule out layoffs.

${ }^{11}$ This subsection follows Snell and Thomas (2009), mutatis mutandis.
} 
Note that there are two cases: if the labour market in sector $m$ at time $t$ clears, $N_{t}^{*}\left(h_{t}\right)=1$, then from (5) $\chi_{t}\left(h_{t}\right)$ must offer the utility offered by other firms. In symmetric equilibrium, other firms are offering an identical contract, and so it is the utility associated with this, $V_{t}^{*}\left(h_{t}\right)$, which must be offered. If, on the other hand, there is excess supply of labour, ${ }^{12} N_{t}^{*}\left(h_{t}\right)<1$, the outside opportunity will depend on the probability of getting a job.

We can summarise:

Definition $1\left(\left(w_{t}^{*^{m}}\left(h_{t}\right)\right)_{t=1}^{T},\left(N_{t}^{* m}\left(h_{t}\right)\right)_{t=1}^{T}\right)_{m=1}^{M}$ constitutes a symmetric (no layoff) equilibrium if it solves Problem DWR for each $m$ where $\left(\chi_{t}^{m}\right)_{t=1}^{T}$ is determined recursively from (1), (5) and (6).

To proceed, we shall provisionally assume that firms always hire (at all $h_{t}$ ) in equilibrium. That is to say, we proceed on the supposition that the constraint (4) in problem DWR never binds in the solution. We characterize the solution if this is the case, and later find conditions on a specific parametrization for which the solution satisfies this property.

Then employment is determined by a standard marginal productivity equation (again suppressing sector superscripts):

Lemma 2 If in a symmetric equilibrium hiring takes place at every $h_{t}$, then $N_{t}^{*}\left(h_{t}\right)$ satisfies

$$
\partial F\left(N_{t}^{*}\left(h_{t}\right), s_{t}\right) / \partial N=w_{t}^{*}\left(h_{t}\right)
$$

Proof. Suppose that $\partial F\left(N_{t}^{*}\left(h_{t}\right), s_{t}\right) / \partial N>w_{t}^{*}\left(h_{t}\right)$. It is feasible to increase current hiring holding the wage contract constant, and consider this as the only change to the firm's plan: An increase in current hiring by $\Delta>0$, for $\Delta$ small enough, and holding the wage constant at $w_{t}^{*}\left(h_{t}\right)$, would lead to an increase in current profits. At the same time, holding employment at $t+1$ constant at $N_{t+1}^{*}\left(h_{t+1}\right)$ in all states (so hiring falls by $\delta \Delta$ ), is feasible for $\Delta$ small enough given hiring is positive at $t+1$. Thus there is an increase in profits at $t$, and no change at other dates, contradicting profit maximization. A symmetric argument, using the fact that current hiring is positive so current hiring can be reduced by $\Delta$, and that $t+1$ employment can be increased by $\delta \Delta$, rules out $\partial F\left(N_{t}^{*}\left(h_{t}\right), s_{t}\right) / \partial N$ $<w_{t}^{*}\left(h_{t}\right)$.

\footnotetext{
${ }^{12}$ Intuitively, the case of excess demand for labour cannot arise in equilibrium, as an infinitessimally small increase in the wage would cure the individual firm's supply problem. In contrast, because of equal treatment the case of excess supply can arise since workers cannot undercut.
} 
Suppose that at some $t$, the participation constraint binds. Then there must be full employment and the wage is determined by marginal productivity at full employment:

Lemma 3 Consider a symmetric equilibrium in which hiring always occurs; then the participation constraint binds at $h_{t}$ if and only if $N_{t}^{*}\left(h_{t}\right)=1$; moreover if the constraint binds then $w_{t}^{*}\left(h_{t}\right)=\partial F\left(1, s_{t}\right) / \partial N$.

Proof. Suppose that $N_{t}^{*}\left(h_{t}\right)<1$. Under the hiring hypothesis, we know from Lemma 2 that $\partial F\left(N_{t}^{*}\left(h_{t}\right), s_{t}\right) / \partial N=w_{t}^{*}\left(h_{t}\right)>\underline{c}$ by the assumption on $\underline{c}$ and diminishing marginal productivity (i.e., $w_{t}^{*}\left(h_{t}\right) \leq \underline{c}$ would imply $N_{t}^{*}\left(h_{t}\right)>1$ ). So a worker who fails to get a job is strictly worse off, and thus $V_{t}^{*}\left(h_{t}\right)>\chi\left(s_{t}\right)$ (cf. (5) and (6)) and so the participation constraint does not bind. On the other hand, if $N_{t}^{*}\left(h_{t}\right)=1$ then from (5), $V_{t}^{*}\left(h_{t}\right)=\chi\left(s_{t}\right)$ and the constraint binds. The equilibrium wage follows directly from Lemma 2.

We define $\underline{w}_{s}^{* m}=\partial F^{m}(1, s) / \partial N$, which in view of the above lemma is the equilibrium wage when the participation constraint binds in state $s$, but note that it would also be the wage in a spot version of the model.

The above is very useful as it tells us that if the contract wage is below the spot wage for that state, we get employment above unity, which is infeasible. So this case cannot occur. If wages are above the spot wage, there is unemployment, and so the participation constraint cannot bind-intuitively a worker who quits is bound to get less utility than she would by not quitting because of the unemployment possibility.

To proceed to an explicit solution, and in order to facilitate the empirical analysis, we put more structure on the problem. ${ }^{13}$ This will allow us to assert that the wage updating rule in any sector $m$ is of the following simple form: given $w_{t}^{*}$ compute $w_{t+1}$ under the hypothesis that the participation constraint at $t+1$ is not binding; if $w_{t+1}>\underline{w}_{s t+1}^{*}$ then the hypothesis is confirmed and $w_{t+1}$ is the equilibrium wage; otherwise the constraint is binding and the equilibrium wage will be at $\underline{w}_{s_{t+1}}^{*}$. The structure will also allow us to demonstrate sufficient conditions for the symmetric hiring equilibrium to exist.

From henceforth assume each firm has technology given by, at time $t$,

$$
F^{m}\left(N, s_{t}\right)=M_{t}^{(m)}+a_{t}^{(m)} N^{1-\alpha} /(1-\alpha)
$$

for $\alpha \neq 1$, with $M_{t} \geq 0$ and for $\alpha=1$, we specify $F^{m}\left(N, s_{t}\right)=a_{t}^{(m)} \log (N) .\left(M_{t}^{(m)}, a_{t}^{(m)}\right)$ is a sector specific shock that depends on the aggregate shock $s_{t}$. Note that for $\alpha>1$,

\footnotetext{
${ }^{13}$ We also need the problem faced by the firm to be concave; concave production and utility functions are not sufficient to guarantee this.
} 
$F^{m}$ has an upper bound given by $M_{t}^{(m)}$, which given that we are modelling short-run production functions at the establishment or plant level, may be appropriate. We assume that productivity shocks are not too bad (again dropping sector superscripts):

$$
a_{t+1} / a_{t}>\delta^{\alpha}
$$

with probability one (for example, with a log production function, this requires only that productivity does not fall at a rate equal to turnover; since the latter is typically estimated in the region of $30 \%$ on an annual basis, this is a mild restriction). This will ensure in the solution derived below, provided wages are sufficiently downward rigid, that firms will always need to hire in new workers (firms always loose more workers through exogenous turnover than they wish to), thus justifying our concentration on hiring equilibria. We also assume henceforth that workers have per-period utility functions of the constant relative risk aversion family with coefficient $\gamma>1$ described by $u(c)=c^{1-\gamma} /(1-\gamma) .{ }^{14}$ Assume $\alpha \gamma>1$.

Under the hiring assumption, we also have that the marginal product of labour equals $a_{t} N_{t}^{-\alpha}$, so that using (7),

$$
N_{t}=a_{t}^{\frac{1}{\alpha}} w_{t}^{-\frac{1}{\alpha}}
$$

Substituting $N_{t}=1$ we find that the spot wage is $\underline{w}_{t}^{*}=a_{t}$.

\subsubsection{No uncertainty}

First we deal with the case of no uncertainty (so that all sectoral productivity sequences are known at date 1 before contracts are entered into). In this case, we show that the wage will always be kept as low as possible subject to it never falling below the spot wage. With downward real rigidity this would imply that the equilibrium satisfies $w\left(h_{t}\right)=$ $\max _{t^{\prime} \leq t} \underline{w}_{s_{t^{\prime}}}^{*}$.

As a first step towards proving this, we demonstrate a frontloading result. The lemma establishes a very useful fact if the model is deterministic: provided the downward constraint is not too weak (for example, with nominal rigidity, provided inflation is not too large), then wages will fall between any two dates by the maximum allowed by the downward constraint unless the participation constraint at the later date binds (we establish this for the case where the constraint (4) is ignored).

The intuition is as follows: if wages next period are not up against the downward constraint, then frontloading them by cutting next period's wage a small amount and

\footnotetext{
${ }^{14}$ For $\gamma=1$, set $u(c)=\log (c)$; all results go through.
} 
simultaneously increasing the current wage to compensate workers does not violate any downward constraints. If in addition next period's participation constraint is not binding then these too will be satisfied at all dates. This will increase profits however. The reason is that because there is turnover - a number of the current workforce will be separated before next period - to compensate workers the current wage does not have to be increased too much as they discount the future wage by the probability of separation, in addition to $\delta$. The firm, however, puts greater weight on wages next period because it will have to pay them to replacement workers (new hires) as well as to the surviving incumbents. Thus the cut in future wages is valued more highly by the firm and profits rise. The argument works so long as (a) wages are not falling too quickly, as then risk-averse workers will need substantial additional compensation now for the steeper wage path, and (b) firms are hiring in new workers. Thus the downward constraint must not have $b\left(h_{t}\right)$ too small, and also negative productivity shocks should not be too severe so that firms want to hire some workers each period, a condition we had already assumed in order to solve the model.

Lemma 4 Suppose there is no uncertainty. Then there exists a $\underline{b}<1$, such that if $b\left(h_{t+1}\right)>\underline{b}$, all $t$, the following must hold: If in a solution for sector $m$ to Problem $D W R$ ' (i.e., DWR without the no layoff constraint) the downward rigidity constraint does not bind in sector $m$ between $t$ and $t+1$ then the participation constraint binds at $t+1$.

Proof. We use time subscripts rather than history dependent functions as there is no uncertainty (and suppress sector $m$ superscripts). Suppose to the contrary of the claim $w_{t}>b_{t} w_{t-1}$ but the participation constraint does not bind at $t+1$. Starting from the optimal contract, consider reshuffling wages between $t$ and $t+1$ as follows: decrease the wage at $t+1$ by a small amount $\Delta w_{t+1}>0$ so that worker utility falls by $\Delta>0$, and increase the wage at $t$ by $\Delta w_{t}$ so that utility rises by $x$, and so as to leave the worker indifferent; do not change the contract otherwise. This implies that

$$
-\delta \beta \Delta+x=0
$$

(where $u^{\prime}\left(w_{t+1}\right) \Delta w_{t+1} \simeq \Delta$ and $u^{\prime}\left(w_{t}\right) \Delta w_{t} \simeq x$ ). This frontloading satisfies all participation constraints: worker utility falls at $t+1$ but the constraint was initially slack by hypothesis, and so from this point on constraints are satisfied; similarly, participation constraints are also satisfied both at $t$ and earlier because utility is held constant over the two periods. A sufficiently small change also satisfies the downward rigidity constraint because at $t+1$ it was slack, while at $t, w_{t}+\Delta w_{t}>w_{t} \geq b_{t} w_{t-1}$, and at $t+2$, $w_{t+1}-\Delta w_{t+1}<w_{t+1} \leq w_{t+2} / b_{t+2}$. We write $\Pi\left(u_{t} ; a_{t}\right)$ as the static profit function at productivity level $a_{t}$ (we can suppress $M_{t}$ which only shifts profits up or down; see (16) below 
for the explicit function) when workers receive a current-period utility of $u_{t}\left(=u\left(w_{t}\right)\right)$, and $N\left(u_{t} ; a_{t}\right)$ for the corresponding optimal labour demand. Because we are ignoring the constraint (4), the optimal contract must generate profits of $\Pi\left(u_{t} ; a_{t}\right)$ at $t$ (the choice of $N_{t}$ does not affect the other constraints, so $N_{t}$ must be chosen to maximise current profits at the contract wage). The change in profits (viewed from $h_{t}$ ) arising from the frontloading is

$$
\Delta P \simeq \beta \Pi^{\prime}\left(u_{t+1} ; a_{t+1}\right) \Delta-\Pi^{\prime}\left(u_{t} ; a_{t}\right) x
$$

Define $\varepsilon:=\min _{2 \leq t \leq T}\left[\delta^{-\alpha} a_{t+1} / a_{t}-1\right]$, where, by (9), $\varepsilon>0$, so that

$$
\delta^{-\alpha} a_{t+1} / a_{t} \geq 1+\varepsilon
$$

From Hotelling's Lemma (converting wages to utilities), $\Pi^{\prime}(u ; a)=-N(u ; a) / u^{\prime}(w)$. Thus,

$$
\frac{\Pi^{\prime}\left(u_{t} ; a_{t+1}\right)}{\Pi^{\prime}\left(u_{t} ; a_{t}\right)}=\frac{N\left(u_{t} ; a_{t+1}\right)}{N\left(u_{t} ; a_{t}\right)}=\frac{a_{t+1}^{\frac{1}{\alpha}}}{a_{t}^{\frac{1}{\alpha}}} \geq \delta(1+\varepsilon)^{1 / \alpha},
$$

where the second equality follows from optimal labour demand $N=a^{\frac{1}{\alpha}} w^{-\frac{1}{\alpha}}$ (given that $u_{t}$ and hence wages are constant in the ratio), and the inequality follows from (13).

Next, $\Pi(\cdot ; a)$ is a concave function: Consider the static problem of maximizing profits given that workers receive utility $u$, so that $w=((1-\gamma) u)^{1 /(1-\gamma)}$. Substituting from the condition that the marginal product of labour equals the wage:

$$
N=a^{\frac{1}{\alpha}} w^{-\frac{1}{\alpha}}
$$

yields profits of

$$
\Pi\left(u ; a_{t}\right) \equiv M_{t}+\frac{a_{t}^{\frac{1}{\alpha}} \alpha((1-\gamma) u)^{-\frac{1-\alpha}{\alpha(1-\gamma)}}}{1-\alpha} .
$$

As $\alpha \gamma>1$, this is a strictly concave function of $u$.

Given that wages rise at a gross rate greater than $b$, then if $\gamma>1$ (so utilities are negative; a similar argument, though with some inequalities reversed, applies for $\gamma<1$ and we omit it),

$$
\frac{u_{t+1}}{u_{t}}=\left(\frac{w_{t+1}}{w_{t}}\right)^{1-\gamma}<b^{1-\gamma}
$$

Then from (16),

$$
\frac{\Pi^{\prime}\left(u_{t+1} ; a_{t+1}\right)}{\Pi^{\prime}\left(u_{t} ; a_{t+1}\right)}=\left(\frac{u_{t+1}}{u_{t}}\right)^{\left(\frac{\alpha \gamma-1}{\alpha(1-\gamma)}\right)}>b^{\left(\frac{\alpha \gamma-1}{\alpha}\right)},
$$


where the inequality follows from (17). Substituting (11) into (12) yields

$$
\begin{aligned}
& \Delta P \simeq \beta \Pi^{\prime}\left(u_{t+1} ; a_{t+1}\right) \Delta-\Pi^{\prime}\left(u_{t} ; a_{t}\right) x \\
= & \beta \Delta \Pi^{\prime}\left(u_{t} ; a_{t}\right)\left(\frac{\Pi^{\prime}\left(u_{t+1} ; a_{t+1}\right)}{\Pi^{\prime}\left(u_{t} ; a_{t}\right)}-\delta\right) \\
> & \beta \Delta \Pi^{\prime}\left(u_{t} ; a_{t}\right)\left(\delta(1+\varepsilon)^{1 / \alpha} b^{\left(\frac{\alpha \gamma-1}{\alpha}\right)}-\delta\right)
\end{aligned}
$$

where the inequality follows from (14) and (18). Thus, provided $b \geq(1+\varepsilon)^{-\frac{1}{\alpha \gamma-1}}, \Delta P>$ 0 . As the initial contract was assumed optimal, this is a contradiction. Given $\alpha \gamma>1$, $(1+\varepsilon)^{-\frac{1}{\alpha \gamma-1}}<1$. Hence setting $\underline{b}=(1+\varepsilon)^{-\frac{1}{\alpha \gamma-1}}$, the assertion of the lemma follows.

We can now show that wages rising by the minimum given by the downward constraint, unless this takes wages below the spot wage in which case the wage is set to the latter, constitutes an equilibrium. We use $\mathrm{a}^{*}$ to denote equilibrium values.

Proposition 5 Suppose there is no uncertainty and that $b\left(h_{t}\right)>\underline{b}$, all $t$. Then there is a symmetric equilibrium in which in each sector $m, w_{t+1}^{* m}=\max \left\{b\left(h_{t+1}\right) w_{t}^{* m}, a_{t+1}^{m}\right\}, t \geq 2$ and $w_{1}^{* m}=a_{1}^{m}$.

Proof. Suppose all other firms follow the putative equilibrium strategy and hire so that they are on their labour demand curves, i.e., marginal product of labour equal to the wage (this defines $\left(\chi_{t}\right)_{t=1}^{T}$ from (5)) and consider the optimal strategy of a potential deviant firm ignoring constraint (4), i.e., a solution to Problem DWR' (which exists by standard arguments) in sector $m$. We show that any optimal strategy must coincide with the putative equilibrium strategy. Again we drop sector superscripts and write $b_{t}$ for $b\left(h_{t}\right)$. (i) If at $T$, the final wage in the deviant strategy $w_{T}<w_{T}^{*}$, then if $w_{T}^{*}=a_{T}$, there is full employment and so to satisfy the participation constraint a wage $w_{T} \geq w_{T}^{*}$ must be paid (see the remark below Lemma 3), so the participation constraint would be violated by the deviation strategy and it would be infeasible; on the other hand, if $w_{T}^{*}<a_{T}$, then at $t-1, w_{T-1}^{*}=w_{T}^{*} / b_{T}$ by definition of the equilibrium strategy, and $w_{T}<w_{T}^{*}$ plus downward rigidity implies $w_{T-1} \leq w_{T} / b_{T}<w_{T}^{*} / b_{T}$, so the deviation contract offers less discounted utility at $T-1$. Again, if the participation constraint binds at $T-1$ for the equilibrium contract, the participation constraint would be violated for the deviant, and if it does not bind, we can extend the argument back to $T-2$, etc. As soon as the participation constraint binds for the putative equilibrium contract (it must bind at $t=1$ by $w_{1}^{*}=a_{1}$, as this implies full employment in the sector and hence by (5) a binding constraint), we will get a contradiction. (ii) If at $T, w_{T}>w_{T}^{*}$, then the participation constraint is slack for the deviant contract and so by Lemma 4 (recall we are looking at 


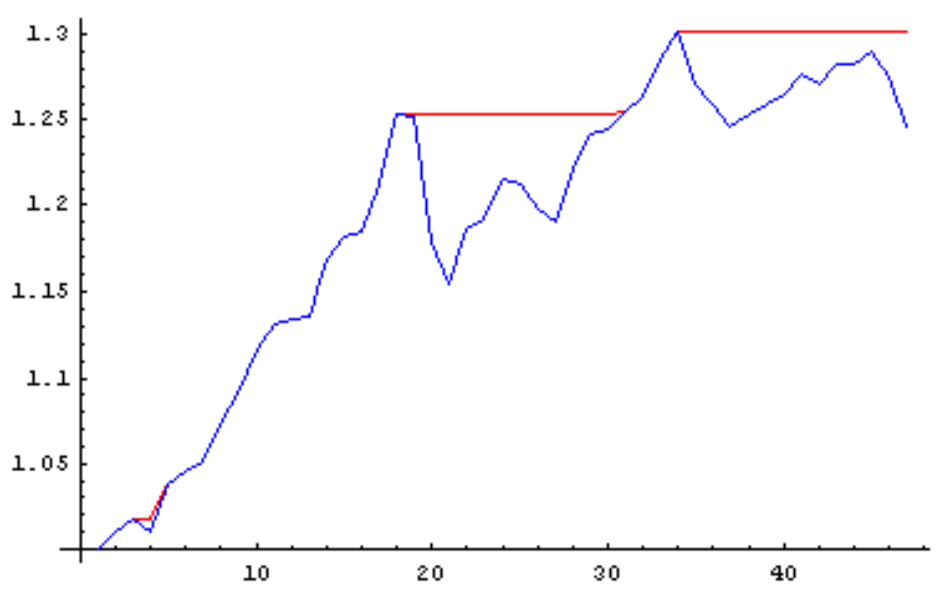

Figure 1: TFP (blue) and wage simulation (red)

an optimal deviation contract, i.e., a solution to Problem DWR'), $w_{T-1}=w_{T} / b_{T}$ and as $w_{T}^{*} \geq b_{T} w_{T-1}^{*}, w_{T-1}>w_{T-1}^{*}$. If at $T-1$ the participation constraint binds for the deviant contract, it would be violated for the equilibrium contract, which is impossible. Thus it cannot bind at $T-1$, and we can work backwards to the point where it last binds for the deviant (it must bind at least at $t=1$ as otherwise cutting $w_{1}$ would improve profits without violating any constraint), at which point again the deviant strategy offers higher discounted utility, a contradiction. We conclude that $w_{T}=w_{T}^{*}$. By similar arguments we can show $w_{T-1}=w_{T-1}^{*}$, and work backward to establish equality of the two contracts. Thus deviation is not profitable.

Finally, since the optimal response to the putative equilibrium contract ignoring the constraint (4) is to adhere to the equilibrium contract, it follows that the same is true when (4) is imposed as it is satisfied in the putative equilibrium from (10) and (9).

To illustrate the solution, we take the actual productivity series for one of the manufacturing sectors that we use in the empirical exercise (see Section 4 for details) and impose full downward rigidity $\left(b\left(h_{t}\right)=1\right)$; Figure 1 displays productivity and simulated wages. The productivity level equals the spot wage, and Proposition 5 says that wages are always at least at this level, and never fall. Whenever the wage lies above productivity, the labor market fails to clear (and the participation constraint does not bind); the larger the percentage gap, the larger is unemployment (as $\left.N_{t}=\left(w_{t} / a_{t}\right)^{-\frac{1}{\alpha}}\right)$. 


\subsubsection{Uncertainty}

The above arguments do not generalise to the case of uncertainty. Lemma 4 may fail as the frontloading of the wage contract between periods $t$ and $t+1$ in a particular state may now affect future wages in other possible states at $t+1$ - the wage at $t$ is increased, so if the downward constraint binds in some other state at $t+1$ this will imply the wage increases in that state, which may be costly. However, we can show that if $T=2$ this problem cannot arise. For simplicity assume $b\left(h_{2}\right)=1$ all $h_{2}$ (downward real rigidity).

Proposition 6 If $T=2$, and $b\left(h_{2}\right)=1$ all $h_{2}$, there is a symmetric equilibrium in which $w_{t}^{*}=\max _{t^{\prime} \leq t} \underline{w}_{t^{\prime}}^{*}$.

Proof. To establish this we convert the firm's choice variable (contract) from wages $\left(w_{t}\left(h_{t}\right)\right)_{t=1}^{2}$ to utilities $\left(u_{t}\left(h_{t}\right)\right)_{t=1}^{2}$. We can formulate Problem $\mathrm{DWR}^{R}$ faced by the firmequivalent to problem DWR except we ignore the no layoff condition (4) - as:

$$
\begin{aligned}
\max _{\left(u_{t}\left(h_{t}\right)\right)_{t=1}^{2}} E\left[\sum_{t=1}^{2}(\beta)^{t-1} \Pi\left(u_{t}\left(h_{t}\right), a_{t}\right)\right] \\
\text { subject to } \quad \tilde{V}_{t}\left(h_{t}\right) \geq \chi\left(h_{t}\right)
\end{aligned}
$$

for all positive probability $h_{t}, 2 \geq t \geq 1$, and

$$
u_{t}\left(h_{t-1}, s\right) \geq u\left(h_{t-1}\right)
$$

where $\tilde{V}_{t}\left(h_{t}\right)$ is defined recursively as before by:

$$
\tilde{V}_{t}\left(h_{t}\right)=u\left(w_{t}\left(h_{t}\right)\right)+\beta_{w} E\left[\delta V_{t+1}\left(h_{t+1}\right)+(1-\delta) \mu \chi_{t+1} \mid h_{t}\right],
$$

with $\tilde{V}_{3}=0$. The maximand is strictly concave (see the proof of Lemma 4) and the constraints are linear. The Slater condition is satisfied by, for all $h_{t}, u_{t}\left(h_{t}\right)=u\left(w^{*}\left(h_{t}\right)+\varepsilon\right)$, for $\varepsilon>0$. Moreover it is straightforward but tedious to show that the Kuhn-Tucker conditions are satisfied at the putative equilibrium contract, hence the putative solution solves Problem DWR ${ }^{R}$ and moreover can be shown to satisfy positive hiring, and so this must also be solution to Problem DWR which has the additional constraint (4).

For $T \geq 3$ we can construct counterexamples to the putative equilibrium, but only if there are shocks sufficiently bad that productivity falls in a range close to $\delta$. We do not have an analytical result however. ${ }^{15}$

\footnotetext{
${ }^{15}$ We simulated models with iid two-state multiplicative productivity processes up to $T=13$. For example, for $\delta=.8$, we confirmed the putative equilibrium for a wided range of other parameter values, provided $a_{t+1} / a_{t}$ was at least approximately .82 with probability one.
} 


\section{Simulations}

In this section we assess to what extent the model is consistent with some relevant labour market stylised facts. In particular, in our first exercise, we gauge whether the version with downward real rigidity (we consider full downward rigidity and a weaker version) can generate a plausible degree of unemployment volatility from measured total factor productivity shocks using US post war aggregate unemployment and TFP data from the Bureau for Labor Statistics (BLS), and how well wage/unemployment regressions on simulated data correspond to existing stylised facts. In a single sector, unemployment falls to zero whenever the productivity shock is not too bad. Using the multisector model, however, in which each sector will be assumed to be subject to an idiosyncratic productivity shock as well as an aggregate shock, we will obtain more realistic unemployment levels because it is less likely that all labour markets will simultaneously clear; moreover when the aggregate productivity shock is positive, there will be more sectors with low unemployment and consequently aggregate employment is likely to be lower. In our second exercise we use actual sectoral manufacturing productivity shocks to generate unemployment data, and compare this with the post-war US experience.

Given knowledge of the model's parameters, given an initial time period where there was full employment and given a TFP series it is possible to generate the sectoral "real wage" series that would be predicted by versions of our theory. We can only assert that this is an equilibrium if there is no uncertainty, so each sectoral sequence is perfectly anticipated, although as noted above, we conjecture that this is also an equilibrium with uncertainty provided shocks are not too negative. It is then possible to derive the corresponding implications for unemployment (rates), and also the relationship between real wages and unemployment.

In accordance with the theory developed earlier,we generate for each sector separate predicted wage and unemployment series, using simulated productivity sequences as deviations around measured TFP data for the U.S. economy, 1949-2001, and then aggregate (we start simulations at full employment and spot wages in 1949, allowing 6 years for unemployment to develop in each sector). Recall that this involves asuming that each sectoral labour market is segmented so we can compute unemployment in each sector independently, and then aggregate.

We examine two distinct relationships between real wages and unemployment over the business cycle. First, studies of real wage cyclicality have mainly looked at how wages respond to contemporaneous unemployment movements. While there is a huge 
literature on this, a very rough summary would be that wages are roughly acyclical, or mildly procyclical, with panel studies tending to suggest the latter. For example, using the PSID for men over the period of 1968-69 to 86-87, Solon, Barsky, and Parker (Feb 1994) found that a one percentage point reduction in the unemployment rate leads to a rise in the real wage rate of 1.4 percent. Similar estimates are found in Shin (Oct 1994) and Devereux (Jul 2001). From our simulations, we can regress real wage changes on changes in unemployment to replicate the typical regression undertaken in the panel studies.

Most studies which use longitudinal data of real wage cyclicality have, following Bils (1985), estimated the following:

$$
\Delta \ln w_{i t}=\beta \Delta U_{t}+\lambda t+\alpha^{\prime} X_{i t}+\varepsilon_{i t},
$$

where $\Delta \ln w_{i t}$ is the difference between the natural logarithm of worker $i$ 's real wage rate in year $t$ and his log real wage in year $t-1, \Delta U_{t}$ is the year-to-year change in the unemployment rate, and $X_{i t}$ is a vector containing an intercept and time varying individual characteristics. The equation also includes a linear time trend (i.e., a corresponding to a quadratic in $t$ in levels).

The second common regression relates wage levels to two lagged measures of unemployment in addition to contemporaneous unemployment. Beaudry and DiNardo (1991) test different versions of a contracting model, which leads to a different regression equation. Their general model can be expressed as follows: the natural log of the real wage for worker $j$ at time $\tau+t$ for a worker who started the job at time $\tau$ satisfies:

$$
\ln w_{j, \tau+t}=\alpha_{1} X_{j, \tau+t}+\alpha_{2} C(\tau, t)+\varepsilon_{j, \tau+t}
$$

where $X_{j, \tau+t}$ is a vector of individual variables, $\alpha_{1}$ is the vector of coefficients on these variables, $\varepsilon_{j, \tau+t}$ is an error term, and $\alpha_{2}$ is the coefficient on the business cycle (i.e., unemployment) variable, with the 3 possibilities for the business cycle variable $C(\tau, t)$ being:

$$
C(\tau, t)= \begin{cases}U_{\tau+t} & \text { spot market model } \\ U_{\tau} & \text { fully binding contract } \\ \min \left\{U_{\tau+k}, k=0,1, \ldots, t\right\} & \text { non-binding on worker }\end{cases}
$$

where the unemployment rate is denoted by $U$, with $U_{\tau}$ the rate prevailing at the start of the job and $U_{\tau+t}$ the rate at time $\tau+t$ where $t$ denotes tenure with the employer. They test these three models against each other on U.S. data (Panel Study on Income Dynamics (PSID)/Current Population Survey (CPS)). The results are striking. In some specifications ${ }^{16}$ in which all three variables are included, the coefficient on the minimum

\footnotetext{
${ }^{16}$ See Table 2 of their paper.
} 
unemployment rate is the only correctly signed (i.e., negative) significant one (PSID, no fixed effects), and in all specifications it is much larger than the other coefficients, implying that a $1 \%$ drop in the minimum unemployment rate (e.g., from $4 \%$ to $3 \%$ ) leads to an increase in current wages of $3 \%$ or more. Several recent empirical studies have largely confirmed the robustness of Beaudry and DiNardo's main empirical findings over different periods and using different datasets, that the minimum rate of unemployment since hiring is a statistically important determinant of the current wage of an individual (McDonald and Worswick 1999, Grant 2003, Shin and Shin 2007, Devereux and Hart 2007), although tending to find a smaller size for the coefficient. Both Grant (2003), and Devereux and Hart (2007), find more of a role for the current unemployment rate than did Beaudry and DiNardo. Grant (2003) extends Beaudry and DiNardo's analysis (using six cohorts from the National Longitudinal Surveys) to cover the time period 1966 to 1998. He finds that the significance and importance of min $u$ is broadly robust to the addition of a number of extra variables.

We ran both regression equations (22) and (23) on our 47 years of simulated data. Since all workers have identical productivity in our model, there are no distinguishing individual characteristics. For (23), we included all three unemployment measures simultaneously, and started the regression in 1968, to allow workers to build up a sufficient history (i.e., the number of workers of each entry vintage in a firm declines with tenure due to the exogenous turnover).

To implement our simulations we need to calibrate $\alpha$, the parameter governing the curvature of the production function. We consider different values: A value of 1.4 translates to a short-run elasticity of demand for labour of approximately -0.7. Estevão and Wilson (1998) analyzing BLS manufacturing data for a similar period that we study, found a short-run demand elasticity ranging between close to zero and -0.71 with aggregate data, and of between -0.5 and -0.89 at the 4-digit industry level for manufacturing, although Hamermesh (1993) reports that an elasticity of around -0.3 is typical. A lower value for $\alpha$ will magnify fluctuations in sectoral unemployment (e.g., if $\alpha$ was calibrated to the labour share in income, assuming a Cobb-Douglas production function involving capital). Note that the value of the risk aversion parameter, $\gamma$, does not affect the solution (it is relevant for the value of $\underline{b}$, however). We also need to specify the productivity process in each sector. We suppose that in each sector $m, a_{t}^{m}$ equals actual TFP (as measured by the BLS for the U.S. economy) times an idiosyncratic component which is modelled as an autoregressive (1) process with persistence of 0.9 and mean 1 . We find the variance of this process to matter to our results (although the persistence does not appear to be 
significant), so we report $\sigma$, the standard deviation of the growth rate in each sector. ${ }^{17}$ We also need to calibrate $\delta$, the exogenous staying rate, in order to run the Beaudry-DiNardo regression (as this determines the numbers of each entry cohort within each firm). We set $\delta=0.7$, corresponding to an annual turnover rate of $30 \%$, which is a fairly typical value. We ran the simulations for 100 sectors, and report mean values of coefficients based on 100 simulations. (The reported coefficients are almost always significant in the simulated regressions.) For most of the simulations we assume full downward rigidity, $b\left(h_{t}\right)=1$, but we also allow a $3 \%$ and $5 \%$ fall per annum respectively, i.e., $b\left(h_{t}\right)=.97 / .95$, and also we finally consider nominal downward rigidity.

The other question we look at is whether the model can generate sufficient degrees of unemployment variability from the underlying process. Since the latter is based on measured TFP, with a large number of sectors the aggregate TFP for our model economy has a similar variability to the measured series (its growth rate has a standard deviation over the sample of $2.3 \%$ when $\sigma=13 \%$ compared with $1.7 \%$ for the underlying TFP series). Thus, we report the variability of simulated aggregate unemployment.

Table 1 presents the results. Actual US Unemployment has a standard deviation of $1.6 \%$ over our sample period. In most of our simulations, the model produces more variability. On the other hand, in the simulations the real wage cyclicality coefficient ( $\beta$ in $(22)$ ), although it is consistently negative, is smaller in absolute value than that typically found in recent longitudinal studies, which as already discussed, would suggest a value closer to -1 . Together these two observations suggest that there is somewhat too much wage rigidity in the model. That the wage semi-elasticity of unemployment is negative in the simulations is unsurprising - with full downward rigidity, for example, wages only change in a sector when there is full employment, in which case they rise. Aggregating across sectors, a fall in unemployment will tend to be associated with more sectors having full employment and consequently wages rising in more sectors.

The coefficients on $C(\tau, t)$ in $(23)$, presented in the final three columns of the table, are often, in existing studies, incorrectly signed (i.e., positive) except for that on minimum unemployment. What we find is that all the reported calibrations produce negative coefficients on unemployment in (22), though again somewhat smaller than that in recent studies. The coefficients in (23) appear, however, to depend on the degree of sectoral productivity variability. If this is sufficiently high, at $\sigma=17 \%$ in the table, the coefficient on minimum unemployment is consistently negative, ${ }^{18}$ whereas the other two coefficients

\footnotetext{
${ }^{17}$ But recall that while we use a random process to generate a sequence of productivity levels, we assume that the sequence is perfectly anticipated.

${ }^{18}$ The reader might be puzzled as to how this is possible given that all workers are paid the same within
} 


\begin{tabular}{l|lllll} 
Model & $\begin{array}{l}\text { Std Dev } \\
\text { of Unem }\end{array}$ & $\begin{array}{l}\text { Wage Cycl. } \\
\text { Coefficient }\end{array}$ & $\begin{array}{l}\text { Min Unem. } \\
\text { Coefficient }\end{array}$ & $\begin{array}{l}\text { Start Unem. } \\
\text { Coefficient }\end{array}$ & $\begin{array}{l}\text { Curr. Unem. } \\
\text { Coefficient }\end{array}$ \\
\hline$\alpha=1.8, \sigma=13 \%$ & $3.8 \%$ & -0.3 & -0.02 & 1.60 & 1.69 \\
$\alpha=1.8, \sigma=17 \%$ & $4.8 \%$ & -0.27 & -0.59 & 2.20 & 1.56 \\
$\alpha=1.8, \sigma=5 \%$ & $1.5 \%$ & -0.50 & 2.84 & -0.14 & -2.14 \\
$\alpha=1.2, \sigma=17 \%$ & $6.2 \%$ & -0.13 & -0.76 & 1.39 & 1.31 \\
$\alpha=0.7, \sigma=3 \%$ & $2.0 \%$ & -0.24 & 0.75 & -0.44 & -1.44 \\
$\alpha=1.8, \sigma=17 \%^{19}$ & $1.8 \%$ & -0.50 & -0.20 & 0.7 & -0.83 \\
$\alpha=1.8, \sigma=22 \%^{20}$ & $1.7 \%$ & -0.41 & -1.01 & 0.43 & -0.22 \\
$\alpha=1.8, \sigma=1 \%^{21}$ & $1.3 \%$ & -0.37 & -0.27 & 1.40 & 1.89
\end{tabular}

Table 1: Simulation Results

are incorrectly signed. This is what Beaudry and DiNardo found in some of their specifications, although the size of the minimum unemployment coefficient is lower than theirs. However, when the variance of the shocks is reduced, we find that the signs reverse. (This is a robust finding across alternative parameterisations).

To get predictions that match better all the stylised facts simultaneously, we found it necessary to relax full downward rigidity, and instead allow respectively $3 \%$ and $5 \%$ p.a. falls (see the penultimate two rows in the table). ${ }^{22}$ As wages can fall, this lessens the amount of unemployment that can develop in a sector, and with it, reduces the variability overall of unemployment closer to the observed magnitude. Finally, in the bottom row, we report results from downward nominal rigidity, but where we have put a maximum fall in real wages of $5 \%$. Again this produces good results, although the coefficient on current unemployment in (23) is positive and large, whereas recent results suggest that a negative coefficient is more reasonable.

To conclude: while the model is capable of reproducing, to an extent, empirically established relationships between wages and unemployment, it requires a high degree variability of sectoral shocks, and such that aggregate unemployment is actually more variable than is empirically plausible unless real wages can fall.

each firm and sector. The answer is that there is variabilty across sectors both of wages and also of proportions employed in each cohort, since sectoral employment histories differ. This is true even of wages at a fixed date: running (23) at a single date produces similar results; this is consistent with Grant (2003), who finds that the minimum unemployment term is robust to the inclusion of time dummies. See Martins, Snell, and Thomas (2005) for further discussion of why the econometric significance of the minumum unemployment rate is not inconsistent with equal treatment models.

${ }^{22}$ Real wage falls in this region do not seem implausible. For example, Elsby (2009) charts the distribution of real wage changes in the PSID over 1983-1992, a relatively low inflation period (so surprise inflation is less likely to lead to unanticipated real wage falls); there is a spike around $2-4 \%$ for real wage falls, and they rarely exceed about 6\%. Likewise Christophides and Stengos (2003) find from Canadian wage contract data in the unionized sector that most real wage reductions in the 1990 s were of the order of $1-2 \%$. 
In a second exercise, rather than simulating a number of sectors and specifying a process for the deviation of sectoral shocks from the economy wide TFP level, we use actual U.S. manufacturing industry multifactor productivity processes for the 17 manufacturing sectors provided by the BLS for the period 1949-2001, ${ }^{23}$ and then aggregate the model's predicted unemployment for each of these sectors using mid-period unemployment shares as weights. ${ }^{24}$ This fixes the variability of shocks and their correlation across sectors, and also allows us to generate a simulated unemployment series which can be directly compared to the data. None of our theoretical results depended on the sectors being of the same size, so our results readily extend to this asymmetric case; indeed allowing sector sizes to vary over time would also be a straightforward extension although we assume they remain constant for the simulations. We consider the case of full downward real rigidity; this means that there is only one degree of freedom, the choice of $\alpha$ - the curvature of the production function. In the figure, we use a logarithmic production function $(\alpha=1)$. However it should be remarked that as manufacturing is only a fraction of the entire economy (and becoming smaller over time), comparing the predicted unemployment rate for our model manufacturing economy with the general unemployment rate, as we do, is inappropriate. Nevertheless, the value of $\alpha$ essentially determines only the extent to which a non-market clearing wage translates into unemployment; it does not affect the equilibrium wage path but only magnifies the unemployment fluctuations as it falls in size. Thus if the remaining economy was composed of a residual sector with constant unemployment, the similar fluctuations in the economy wide unemployment rate would result from choosing a lower value for $\alpha$. The results are presented in Figure 2.

Given there is only one degree of freedom (together with an assumed constant fricitional rate of unemployment which shifts the simulated series up or down), the simulation tracks unemployment surprisingly well until towards the end of the simulation. Allowing wages to fall somewhat reduces simulated unemployment particularly towards the end of the simulation. What seems to be happening in the displayed case is that some sectors experience a sufficiently long trend of poor productivity shocks that unemployment in those sectors builds up with completely downward rigid wages, but this does not happen with some degree of flexibility. It is clearly unrealistic to suppose that labour wouldn't in the long-run move out of these sectors, so even if downward rigidity was appropriate we should expect to see lower unemployment towards the end of the period than the

\footnotetext{
${ }^{23}$ This is the only sectoral TFP series available for such a long time scale and collected on a consistent basis.

${ }^{24}$ As before we run the model for 6 years starting from full employment in each sector, to allow unemployment to evolve; so again we have simulations for 1955-2001. We add 3.5\% to represent a constant frictional rate.
} 


\section{Unemployment (\%)}

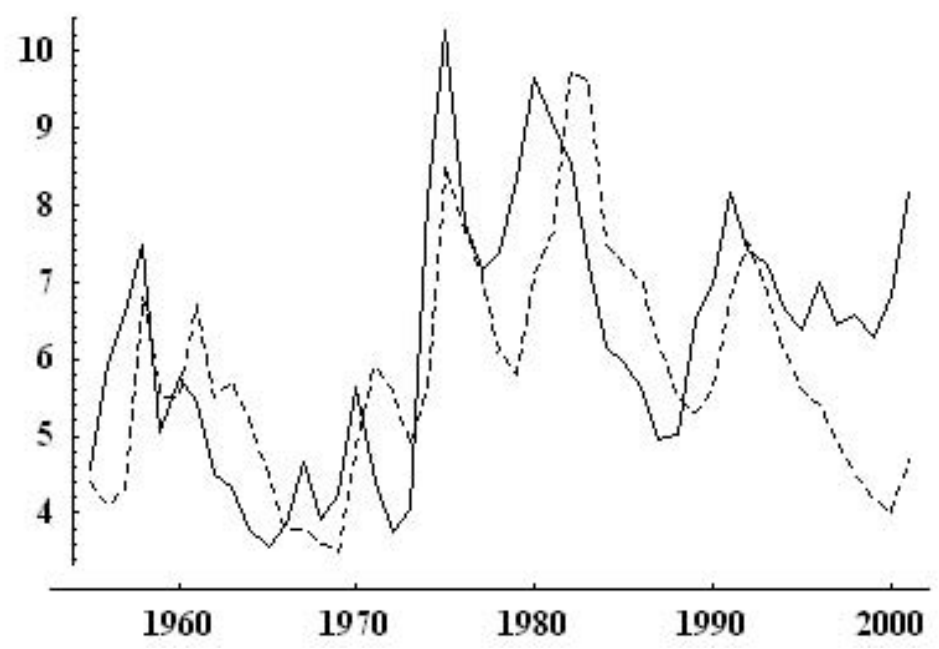

Figure 2: Unemployment simulations (solid line) and actual annual US rate (broken line), 1955-2001

simulation suggests.

The simulation of this second exercise does not possess sufficient sectoral productivity variability to generate reasonable wage regression coefficients, particularly for the BeaudryDiNardo regressions. One resolution, to be postponed for future work, might be to add idiosyncratic firm shocks within each sector, as variation in the hiring rates over time are important for the outcome. And we know that at the firm level, there is substantial variability as far as labour flows are concerned (Davis, Haltiwanger, and Schuh (1996)).

Finally, we note that broadly similar unemployment simulations as in our second exercise were obtained in Snell and Thomas (2009). However, there, to avoid wages falling too fast, it was necessary to either assume that workers are very risk averse (formally, as worker risk-aversion tends to infinity the solution converges to our model with full downward rigidity (and even with uncertainty the simple characterisation obtains), or that workers discount the future less than firms, or it was necessary to augment the model with heterogenous worker turnover rates. In addition there were a number of degrees of freedom in terms of parameter values compared to the current model. What this paper suggests, nevertheless, is that introducing an independent source of downward rigidity avoids having to make these assumptions. 


\section{Concluding Comments}

This paper has analysed a model with downward rigidities in which firms cannot pay discriminate based on year of entry to a firm. We solved for the dynamics of wages and unemployment under conditions of downward wage rigidity, where forward looking firms take into account these constraints. We found that the equilibrium could be solved for under conditions of certainty. Using simulated and actual productivity data based on the post-war US economy, we analysed the ability of the model to match certain stylised labour market facts, and found that it was able to generate sufficient variability of unemployment, but could only match other stylised facts when full downward rigidity is relaxed somewhat.

\section{References}

Agell, J., And P. Lundborg (2003): "Survey evidence on wage rigidity and unemployment: Sweden in the 1990s," Scandinavian Journal of Economics, 105, 15-29.

Akerlof, G. A., And J. L. Yellen (1990): "The Fair Wage," Quarterly Journal of Economics, 55, 255-283.

Baker, G., M. Gibbs, and B. Holmstrom (1994): "The wage policy of a firm," Quarterly Journal of Economics, 109, 921-955.

Beaudry, P., and J. DiNardo (1991): "The Effect of Implicit Contracts on the Movement of Wages over the Business-cycle - Evidence from Micro Data," Journal of Political Economy, 99, 665-688.

Bewley, T. F. (1999a): Why Wages Don't Fall During a Recession. Harvard University Press, Harvard.

Bewley, T. F. (1999b): "Work Motivation," Federal reserve Bank of St. Louis Review, $81(3), 35-50$.

Bils, M. J. (1985): "Real Wages over the Business Cycle: Evidence from Panel Data," Journal of Political Economy, 93(4), 666-689.

Christophides, L. N., And T. Stengos (2003): "Wage rigidity in Canadian collective bargaining agreements," Industrial and Labor Relations Review, 56(3), 429-448.

Davis, S. J., J. C. Haltiwanger, and S. Schuh (1996): Job Creation and Destruction, MIT Press Books. Cambridge MA: The MIT Press. 
Devereux, P. J. (Jul 2001): "The cyclicality of real wages within employer-employee matches," Industrial Labor Relations Review, 54, 835-850.

Devereux, P. J., and R. A. Hart (2007): "The Spot Market Matters: Evidence on Implicit Contracts from Britain," Scottish Journal of Political Economy, 54(5), 661-683.

Elsby, M. W., R. Michaels, and G. Solon (2009): "The Ins and Outs of Cyclical Unemployment," American Economic Journal: Macroeconomics, 1(1), 84-110.

Elsby, M. W. L. (2009): "Evaluating the Economic Significance of Downward Nominal Wage Rigidity," Journal of Monetary Economics, 56(2), 154-169.

Estevão, M. M., And B. A. Wilson (1998): "A Note on Nominal Wage Rigidity and Real Wage Cyclicality," Working paper, board of governors of the federal reserve system.

Gertler, M., and A. Trigari (2009): "Unemployment Fluctuations with Staggered Nash Wage Bargaining," Journal of Political Economy, 117(1), 38-86.

Gottfries, N., and T. Sjostrom (2000): "Insider Bargaining Power, Starting Wages, and Involuntary Unemployment," Scandinavian Journal of Economics, 102, 669-688.

Grant, D. (2003): "The Effect of Implicit Contracts on the Movement of wages over the Business Cycle: Evidence from National Longtitudinal Surveys," Industrial and Labor Relations Review, 56(3), 393-408.

Haefke, C., M. Sonntag, and T. van Rens (2007): "Wage Rigidity and Job Creation," Economics Working Papers 1047, Department of Economics and Business, Universitat Pompeu Fabra.

Hall, R. E. (2005a): "Employment Fluctuations with Equilibrium Wage Stickiness," American Economic Review, 95(1), 50-65.

Hall, R. E. (2005b): "Job Loss, Job Finding, and Unemployment in the U.S. Economy over the Past Fifty Years," NBER Macroeconomics Annual, pp. 101-137.

Hamermesh, D. (1993): Labor Demand. Princeton University Press, Princeton.

Kaufman, R. (1984): "On Wage Stickiness in Britain's Competitive Sector," British Journal of Industrial Relations, 22, 101-112.

Kwon, I., and E. M. M. Milgrom (2005): "Cohort Effects and Catch-ups in Wages and Promotions," Department of Economics, University of Michigan. 
Martins, P., A. Snell, and J. P. Thomas (2005): "Wage Dynamics, Cohort Effects, and Limited Commitment Models," Journal of the European Economic Association, $3(2-3), 350-359$.

McDonald, J. T., and C. Worswick (1999): "Wages, Implicit Contracts, and the Business Cycle: Evidence from Canadian Micro Data," The Journal of Political Economy, 107, 884-892.

Menzio, G., And E. Moen (2008): "Worker Replacement," PIER Working Paper 08-040, October 2008.

Pissarides, C. (1986): "Unemployment and Vacancies in Britain," Economic Policy, $1(3), 499-599$.

Pissarides, C. A. (2007): "The Unemployment Volatility Puzzle: Is Wage Stickiness the Answer?," CEP Discussion Papers dp0839, Centre for Economic Performance, LSE.

Shimer, R. (2005a): "The Cyclical Behavior of Equilibrium Unemployment and Vacancies," American Economic Review, 95(1), 25-49.

(2005b): "Reassessing the Ins and Outs of Unemployment," Mimeo, University of Chicago.

Shin, D. (Oct 1994): "Cyclicality of real wages among young men," Economics Letters, 46, 137-142.

Shin, D., And K. Shin (2007): "Why are the wages of job stayers procyclical?," Macroeconomic Dynamics, 11, forthcoming.

Snell, A., and J. P. Thomas (2009): "Labor Contracts, Equal Treatment and WageUnemployment Dynamics," American Economic Journal: Macroeconomics, forthcoming.

Solon, G., R. Barsky, and J. A. Parker (Feb 1994): "Measuring the cyclicality of real wages: how important is composition bias?," Quarterly Journal of Economics, 109, $1-26$.

Wachter, T. V., and S. Bender (2008): "Do initial conditions persist between firms? An analysis of firm-entry cohort effects and job losers using matched employer-employee data," in The Analysis of Firms and Employees: Quantitative and Qualitative Approaches. University Chicago Press. 